\title{
DESIGN OF CONTROL SYSTEM OF LASER LEVELING MACHINE BASED ON FUSSY CONTROL THEORY
}

\author{
Yongsheng $\mathrm{Si}^{1}$, Gang Liu ${ }^{2,3, *}$, Jianhan Lin ${ }^{2,3}$, Qingfei Lv ${ }^{4}$, Feng Juan ${ }^{1}$ \\ ${ }^{1}$ Agriculture University of Hebei, Baoding, China, 071001 \\ ${ }^{2}$ College of Information and Electrical Engineering, China Agricultural University, Beijing, \\ China, 100083 \\ ${ }^{3}$ Key Laboratory of Modern Precision Agriculture System Integration Research, Beijing, \\ 100035, China \\ ${ }^{4}$ Hangzhou Dianzi University, Hangzhou, 310018, China \\ * Corresponding author, Address: P.O. Box 125, China Agricultural University, 17 Tsinghua \\ East Road, Beijing, 100083, P. R. China, Tel: +86-10-62736741, Fax: +86-10-62736746, \\ Email:pac@cau.edu.cn
}

Abstract: The control system of laser leveling machine was redesigned and tested to improve the performance and decrease the cost. In this paper, the control system of the machine which contains transmitter, receiver and controller was introduced. The receiver had silicon photoelements as photoelectric sensors. A kind of light filter was designed which was composed of red color optical glass and interference filter. Fussy control theory was applied in the controller design. The experiments conducted in fields showed that the controller and the laser receiver developed matched well. The control system worked well and the leveling accuracy was improved.

Keywords: fussy control, leveling machine, laser-controlled

\section{INTRODUCTION}

Land leveling, which is an important method to improve water coverage in field, can improve the irrigation efficiency and uniformity (Xu, 1999). Research has shown large decrease in water consumption and large increase in crop yield and quantity due to good field leveling. The sensitivity of the laser sensor system is at least 10 to 50 times more precise than the visual

Si, Y., Liu, G., Lin, J., Lv, Q. and Juan, F., 2008, in IFIP International Federation for Information Processing, Volume 259; Computer and Computing Technologies in Agriculture, Vol. 2; Daoliang Li; (Boston: Springer), pp. 1121-1127. 
judgment and manual hydraulic control of an operator on the tractor. Consequently, the land leveling operation is correspondingly more accurate (Walker, 1992). Laser controlled land leveling technology has been already used widely abroad. In China, some farms and departments have imported laser controlled land leveling machine to conduct land leveling experiments since the eighties of the 20th century, while this technology was not popularized for the reason of high price. The water resource is scarce seriously in China, it is necessary to develop low-cost laser controlled leveling system with independent intellectual property right to improve the efficiency of water utilization and raise the crop yield.

The laser leveling system (Fig. 1) is composed of laser transmitter, laser receiver, controller, hydraulic system and bucket. The laser transmitter transmits a laser beam, which is intercepted by the laser receiver mounted on the leveling bucket. The controller mounted on the tractor interprets the signals from the receiver and opens or closes the hydraulic control valve, which will raise or lower the bucket. The controller transmits various control signals to the hydraulic system according to the signals received from the receiver and deals with unusual information. The transmitter, receiver and controller, which constitute the control system of the machine, take large proportion in cost of the system and play a important role in the machine. A domestic product - JP3 Rotation Laser was selected as the transmitter to lower the cost. This paper introduces the development of the receiver, the controller and the experiments analysis of the machine.

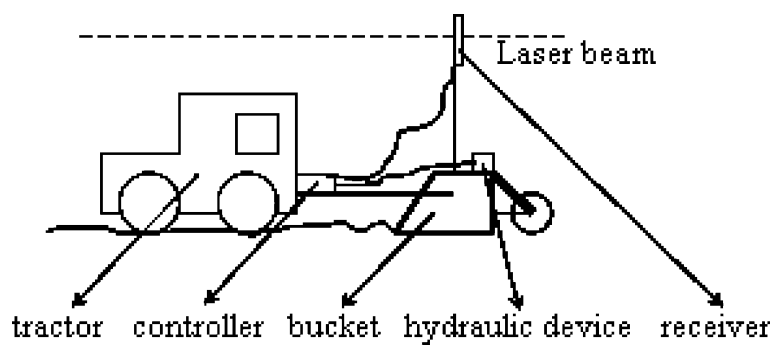

Fig. 1. Laser leveling machine

\section{DESIGN OF CONTROL SYSTEM}

\subsection{Hardware Design of Receiver}

The receiver had 8 layers with 32 pieces of silicon photoelements as photoelectric sensors (Lin, 2006). Laser filter was installed on the receiving surface of each photoelement. Each photoelement was designed to work with 
angle range no less than 90 degrees. In this way the whole working angle of each layer of photoelements comes up to 360 degrees (Fig. 2).

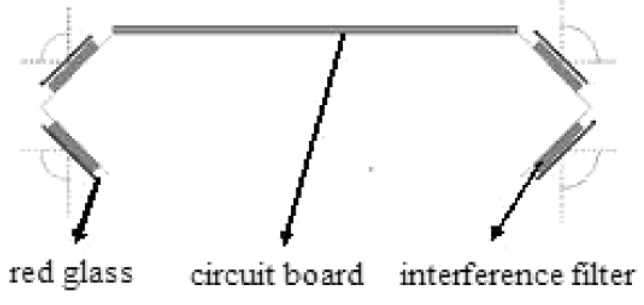

Fig. 2. Planform of receiver

The key problem in receiver design was to avoid or weaken the interference of sunlight. When developing the receiver, 2CR93 silicon photoelements were used to receive the laser signals which indicated the relative heights of the leveling scraper. The price of the interference filter is related with half-bandwidth, transmission rate and depth of the background. In order to lower the cost of the receiver, a kind of light filter, which was composed of red color optical glass and interference filter, was designed to restrict most noisy rays. A signal processing circuit was designed to amplify four channels of low-power analog signals from photoelements and process them into four channels of digital height signals respectively (Fig. 3).

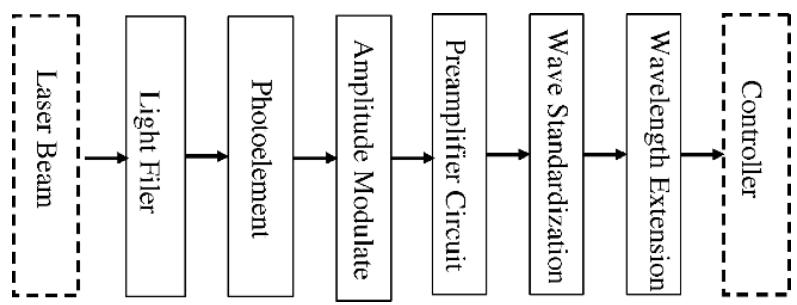

Fig. 3. Block diagram of receiver

\subsection{Hardware Design of Controller}

The controller raises or lowers the bucket by controlling the hydraulic system according to the signals received from the receiver. The controller is composed of CPU (89S51), pre-processing circuit, watchdog circuit, memory circuit, interlocking circuit, drive circuit and solid state relay (SSR) circuit etc. ( $\mathrm{Si}, 2004)$. In many cases, the operator need control the system manually. For instance, if the depth of cutting exceeds the depth which can be cut with the power of the tractor and the operator must override the automatic controls in order to keep the equipment operating. Auto/Manual switch circuit was designed for the reason above. There are two output signal 
channels in the system. At any time, only one channel is positive signal, otherwise the hydraulic system will be destroyed. The controller has memory function to record the topographic data. Fm24C16 was selected as the memory chip. Fm24c16 is a 16-kilobit nonvolatile memory employing an advanced ferroelectric process. Two DC Solid State Relays (SSR) are used in the system to drive the electromagnetic valves (Lin, 2004).

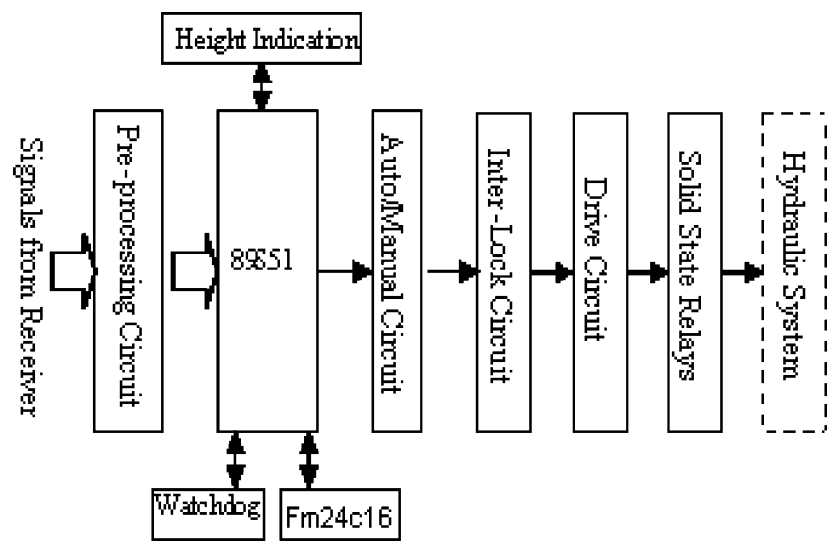

Fig. 4. Block diagram of controller

\subsection{Design for Fuzzification}

The controller can judge the position of the bucket, which indicates the height of the field, according to the signals received from the receiver. The controller controls the moving time by controlling the working time of the electromagnetic valves. To increase working efficiency and reduce the wearing and tearing of the equipments, the system has Rough/Precision leveling switch functions. The function of fuzzificaton is to translate e (the deviation between the measured height of the field and the expected height of the field) and etc. (the changing rate deviation between the measured height of the field and the expected height of the field) into the language variables $\mathrm{E}$ and $\mathrm{EC}$, where the language variables are the fuzzy terminologies, such as "Very High", "High", "Low", "Very Low", and so on. Nine fuzzy sets are defined for the language E: positive very big (PVB), positive big (PB), positive middle (PM) and positive small (PS), zero (ZE), negative small (NS), negative middle (NM), negative big (NB) and negative very big (NVB). Two fuzzy sets are defined for the language EC: positive big (PB) and positive small (PS). The language U (compensation quantity of working time of the electromagnetic valves) are divided into nine optimal fuzzy areas: left full open(LFO), left long open (LLO), left middle open (LMO), left short open (LSO), all close (AC), right short open (RSO), right middle open (RMO), right long open (RLO) and right full open (RFO). 


\subsection{Design of Control Rules}

Based on a great deal of experimental data and based on the principle of responding fast and working stable, the optimal working frequency of $8 \mathrm{MHz}$ was selected (Lv, 2005). The electromagnetic valves and the hydraulic system work well at this frequency. The system has two working modes: rough leveling and precision leveling. Higher accuracy can be got under the precision leveling mode and under rough leveling mode the system has high working efficiency and low wearing and tearing of the equipments. Under the precision leveling mode, the hydraulic system and the bucket act more frequently than under the rough mode. The system can switch the two modes automatically according to the EC. The fuzzy control rules were summarized and shown in Table 1.

Table 1. Fuzzy control rules

\begin{tabular}{lccc}
\hline & $\mathrm{U}$ & \multicolumn{2}{c}{ EC } \\
\cline { 3 - 4 } & PVB & PS & PB \\
\hline & PB & LFO & LLO \\
PM & LLO & LLO \\
& LMO & LLO \\
& PS & LSO & LLO \\
E & AC & AC \\
& NS & RSO & RLO \\
& NM & RMO & RLO \\
& NB & RLO & RLO \\
\hline
\end{tabular}

\section{EXPERIMENTS AND RESULTS}

Experiments have been conducted in Beijing Shangzhuang Experiment Station on 2 May 2007 to check the efficiency and quality of the new control system. During the experiments we used the bucket and other parts of the leveling machine made by China Agriculture University. There are two parameters to evaluate the quality of field leveling. One is $\mathrm{Sd}$ (standard deviation) ( $\mathrm{Li}, 1999)$ :

$$
S_{d}=\sqrt{\sum_{i=1}^{n}\left(h_{i}-\bar{h}\right)^{2} /(n-1)}
$$

Where hi represents the ith height measured, is the mean height and $n$ is the number measured. The other parameter is $\mathrm{P}$ (percentage):

$$
P=n_{c} / n
$$


Where $n_{c}$ represents the number of points whose absolute difference, between the measured height and the mean height, is less than a certain value. Before and after the leveling, the experiment field was partitioned into many square grids, whose sides are 10 meters. The field height was measured at every corner point. The experiment data were shown in Table 2 and Table 3.

Table 2. Heights of measured points before leveling $(\mathrm{cm})$

\begin{tabular}{ccccc}
\hline $\mathrm{hxy}$ & $\mathrm{x}=0$ & $\mathrm{x}=1$ & $\mathrm{x}=2$ & $\mathrm{x}=3$ \\
\hline $\mathrm{y}=0$ & 135.5 & 146.5 & 142 & 142.5 \\
$\mathrm{y}=1$ & 139 & 138.5 & 133 & 141 \\
$\mathrm{y}=2$ & 141 & 140 & 135 & 135.5 \\
$\mathrm{y}=3$ & 140 & 133 & 137.5 & 132 \\
$\mathrm{y}=4$ & 141.5 & 138 & 139 & 140 \\
$\mathrm{y}=5$ & 142 & 141.5 & 145 & 135.5 \\
$\mathrm{y}=6$ & 141.5 & 141 & 135 & 139.5 \\
$\mathrm{y}=7$ & 141.5 & 140 & 140 & 139 \\
$\mathrm{y}=8$ & 142 & 138 & 138 & 135.5 \\
$\mathrm{y}=9$ & 139.5 & 140 & 135.5 & 139 \\
$\mathrm{y}=10$ & 142 & 138.5 & 139 & 135.5 \\
$\mathrm{y}=11$ & 142 & 141.5 & 143 & 140 \\
$\mathrm{y}=12$ & 137.5 & 143 & 140 & 137.5 \\
\hline
\end{tabular}

The $\mathrm{Sd}$ (standard deviation) before leveling is $3.03 \mathrm{~cm}$ and the $\mathrm{Sd}$ after leveling is $0.48 \mathrm{~cm}$. Before and after the leveling, the percentage of the number of the points whose absolute difference between the measured height and the mean height less than $1.5 \mathrm{~cm}$ is $38 \%$ and $100 \%$ respectively. The performance of leveling distribution was very good for the max percentage of the absolute difference of other leveling machines was less than $80 \%$ (Dedrick et al., 1982).

Table 3. Heights of measured points after leveling $(\mathrm{cm})$

\begin{tabular}{ccccc}
\hline hxy & $\mathrm{x}=0$ & $\mathrm{x}=1$ & $\mathrm{x}=2$ & $\mathrm{x}=3$ \\
\hline $\mathrm{y}=0$ & 175 & 175 & 175 & 176 \\
$\mathrm{y}=1$ & 175.5 & 175 & 174.5 & 175 \\
$\mathrm{y}=2$ & 175 & 175 & 175.5 & 175 \\
$\mathrm{y}=3$ & 175 & 174.5 & 175.5 & 175.5 \\
$\mathrm{y}=4$ & 176.5 & 175 & 175 & 174.5 \\
$\mathrm{y}=5$ & 176 & 175 & 175 & 175 \\
$\mathrm{y}=6$ & 175.5 & 175 & 175 & 176 \\
$\mathrm{y}=7$ & 175 & 174.5 & 175 & 175.5 \\
$\mathrm{y}=8$ & 176 & 175.5 & 175.5 & 175 \\
$\mathrm{y}=9$ & 176 & 175.5 & 175.5 & 175.5 \\
$\mathrm{y}=10$ & 176.5 & 176 & 175.5 & 175.5 \\
$\mathrm{y}=11$ & 175.5 & 176 & 175 & 175.5 \\
$\mathrm{y}=12$ & 175.5 & 175 & 175 & 176 \\
\hline
\end{tabular}




\section{CONCLUSION AND FUTURE WORK}

The cost of the control system was reduced through the new design of the receiver. The control system matched the other parts of the leveling machine well. High accuracy was got through fuzzy control system during the experiments. The performance of leveling distribution was highly improved especially. Moreover, the application of fuzzy control theory made the system more intelligent and the labor intensity was reduced. In this experiment the field is a regularly sized and shaped field. To test the performance of the control system and to make the control system more stable, more experiments should be conducted in different conditions, such as glutinous field and sandy field, dry field and moist field, field with and without straw and weed and so on, because leveling accuracy is high related with the field condition before leveling. It should be mentioned that the leveling efficiency and the result were high related with the operator and in this experiment the operator was experienced.

\section{ACKNOWLEDGEMENTS}

This paper is funded by the national 863 projects: Laser Controlled Land Leveling and Precision Surface Irrigation Equipment. (2006AA100210).

\section{REFERENCES}

Dedrick A R, Erie L J, and Clemmens A J, Lever basin irrigation. In Advances in Irrigation. Vol. 2, Hillel D I, ed, Acade mic Press, 1982, New York.

Li Yinong, Xu Di. Application and Evaluation of Laser Controlled Leveling Technology. Transactions of the Chinese Society of Agricultural Engineering 1999 6: pp. 79-83 (in Chinese).

Lin Jianhan, Liu Gang. A lower-cost controlled system for laser leveling, 2004 CIGR International conference Beijing, 2004.10.

Lin Jianhan, Wang Maohua, Liu Gang, Si Yongsheng. Development of a Laser Controlled System for Land Leveling Machinery, CIGR World Congress 2006, 2006.8

Qingfei Lv, Gang Liu, Jianhan Lin. An Innovated Laser Control System for Land Leveling Equipment, The International Symposium on Innovation and Development of Citied Agricultural, 2005.10.

Si yongsheng, Liu Gang, Lian Jianhan. Research on controller of laser leveling system, 2004 CIGR International conference Beijing, 2004.10.

Walker W R. Guidelines for designing and evaluating surface irrigation systems. FAO Irrigation and Drainage Paper No. 45, 1992, Rome.

Xu Di, Li Yinong, Li Fuxiang etc, Study on combination of conventional and Laser-controlled land grading procedures. Journal of Hydraulic Engineering 1999 10:52-56 (in Chinese) 